\title{
Comparison of clinical characteristics, in-hospital course, and 12-month prognosis in women and men with chronic coronary syndromes
}

\author{
Dominika Duda-Pyszny¹, Przemysław Trzeciak¹, Piotr Desperak¹, Michał Zembala², Mariusz Gąsior ${ }^{1}$ \\ $13 r d$ Department of Cardiology, Faculty of Medical Sciences in Zabrze, Medical University of Silesia, Katowice, Poland \\ 2 Department of Cardiac, Vascular and Endovascular Surgery and Transplantation, Silesian Center for Heart Diseases, School \\ of Medicine with the Division of Dentistry in Zabrze, Medical University of Silesia, Katowice, Poland
}

\section{KEY WORDS \\ chronic coronary syndromes, comparison, men, prognosis, women}

\section{EDITORIALS}

by Andreotti et al, see p. 373 and Ferrari, see p. 376

Correspondence to: Dominika Duda-Pyszny, MD, 3rd Department of Cardiology, Faculty of Medical Sciences in Zabrze, Medical University of Silesia, Katowice, Poland phone: +48323733860, email: duda.dominika@wp.pl Received: November 28, 2020. Revision accepted: December 31, 2020. Published online: January 15, 2021. Kardiol Pol. 2021; 79 (4): 393-400 doi:10.33963/KP.15749 Copyright by the Author(s), 2021

\begin{abstract}
BACKGROUND The prognosis of men and women with chronic coronary syndromes (CCS) remains ambiguous.

AIMS This study aimed to compare the clinical characteristics and 12-month prognosis of women and men with CCS included in the prospective single-center registry.

METHODS The study was based on the Prospective Registry of Stable Angina Management and Treatment (PRESAGE) including 11021 patients with CCS hospitalized between 2006 and 2016 and subjected to coronary angiography. The composite endpoint included all-cause death, nonfatal myocardial infarction, acute coronary syndrome with revascularization, unstable coronary artery disease, or stroke.

RESULTS Women were older than men (mean [SD] age, 66.6 [9] vs 63.5 [9.6] years; $P<0.001$ ). Arterial hypertension ( $85.8 \%$ vs $79 \% ; P<0.001)$ and type 2 diabetes ( $38.2 \%$ vs $33.7 \% ; P<0.001$ ) were more often diagnosed in women compared with men. Multivessel disease or left main disease were more frequent in men. Percutaneous coronary intervention and coronary artery bypass grafting were more often performed in men than in women ( $47.1 \%$ vs $36 \%, P<0.001$ and $10.6 \%$ vs $6.1 \%, P<0.001$, respectively). At 12-month follow-up, the composite endpoint was more frequently reached in men (7.4\% vs $10.2 \%$; $P<0.001$ ), including death (3.3\% vs 4.5\%; $P=0.002$ ). In multivariable analysis, sex was not an independent predictor of the composite endpoint (hazard ratio, 1.08; 95\% CI, 0.89-1.31, $P=0.45$ ).

CONCLUSIONS Women and men with CCS differ in terms of the incidence of risk factors and revascularization treatments received. In men, a higher frequency of death and the composite endpoint was noted at 12-month follow-up. However, sex was not an independent predictor of patient outcomes at 12 months.
\end{abstract}

INTRODUCTION The prognosis of women and men with chronic coronary syndromes (CCS) remains ambiguous in the light of the available data. There are few studies focusing on the differences in long-term prognosis between men and women with coronary artery disease (CAD) and the results of those analyses are often inconclusive. ${ }^{1-3}$ Therefore, the aim of our study was to compare clinical characteristics, in-hospital complications, and 12-month prognosis in women and men with CCS included in the prospective single-center registry.

METHODS Registry design and study popuIation The Prospective Registry of Stable Angina Management and Treatment (PRESAGE), maintained by 3rd Department of Cardiology, 


\section{WHAT'S NEW?}

The Prospective Registry of Stable Angina Management and Treatment (PRESAGE) includes patients diagnosed with chronic coronary syndromes and subjected to coronary angiography during hospitalization. Our registry-based study showed that men and women represent heterogenous groups with varied clinical characteristics. What is more, sex was not an independent predictor of 12-month outcomes in multivariable analysis.

Medical University of Silesia, Silesian Center for Heart Diseases in Zabrze, Poland, includes patients diagnosed with CCS who underwent coronary angiography during hospitalization.

The diagnosis of CCS was established based on the current guidelines of the European Society of Cardiology. ${ }^{4}$ Patients with vasospastic and/or microvascular angina were additionally entered in the registry. Patients presenting to our center several times were assessed as a single patient (data from the first hospitalization were included). The study was approved by an appropriate institutional review board. Patient consent to participate in the study was not required.

Women and men were compared in terms of clinical characteristics, angiographic findings, revascularization, in-hospital complications, and pharmacological recommendations at discharge from the hospital. The comparison of 12-month prognosis was based on the assessment of the incidence of a composite endpoint that consisted of all-cause death, nonfatal myocardial infarction (MI), acute coronary syndrome (ACS)-driven revascularization, unstable angina, or stroke. Independent factors influencing the occurrence of a composite endpoint during the 12-month follow-up were evaluated in a multivariable analysis. Data concerning the 12-month follow-up were obtained from the Polish National Health Fund (Polish, Narodowy Fundusz Zdrowia). Due to the preliminary assumptions of our analysis, we decided to follow up the study population for 12 months. There was no difference in the duration of follow-up between women and men.

Definitions Myocardial infarction was diagnosed in accordance with the current guidelines of the European Society of Cardiology. ${ }^{5,6}$ Acute coronary syndrome-driven revascularization was defined as acute myocardial ischemia requiring urgent percutaneous coronary intervention (PCI) or coronary artery bypass grafting ( $C A B G)$. Unstable angina was diagnosed in the case of an acute myocardial ischemia episode manifested by acute ischemic changes on electrocardiography, with no biomarkers of myocardial injury present. Stroke was regarded as acute ischemia or bleeding into the central nervous system. The diagnosis of hypertension was established when repeated arterial pressure values of at least 140/90 $\mathrm{mm} \mathrm{Hg}$ were noted or the patient used hypotensive drugs. Type 2 diabetes was diagnosed when the level of fasting glucose was 2-fold higher than $125 \mathrm{mg} / \mathrm{dl}$ or the level of casual plasma glucose exceeded $200 \mathrm{mg} / \mathrm{dl}$, or the patient had already been using antidiabetic drugs or insulin. Hypercholesterolemia was identified when total cholesterol levels exceeded $200 \mathrm{mg} / \mathrm{dl}$ and/or low-density lipoprotein cholesterol levels were above $130 \mathrm{mg} / \mathrm{dl}$, or lower values were achieved using statins. Obesity was diagnosed when the body mass index exceeded $30 \mathrm{~kg} / \mathrm{m}^{2}$. A positive family history of premature $C A D$ was regarded as the occurrence of CAD under 50 years of age in men and under 60 years of age in women. Significant $C A D$ was diagnosed in the presence of $70 \%$ stenosis or greater in an artery with a reference diameter of more than $2 \mathrm{~mm}$ or in the presence of $50 \%$ stenosis or greater in the left main coronary artery or left anterior descending artery. Bleeding during hospitalization was considered significant if hemoglobin levels dropped below $5 \mathrm{~g} / \mathrm{dl}$ and / or hematocrit levels decreased by more than $15 \%$, leading to hemorrhagic shock and / or condition requiring blood transfusion.

Statistical analysis Statistical analysis included descriptive statistics of baseline characteristics, angiographic findings, management, in-hospital events as well as the occurrence and predictors of adverse events during the 12-month follow-up. Continuous variables were expressed as mean (SD) for data following normal distribution or median (interquartile range [IQR]) for data demonstrating nonnormal distribution. Continuous variables with normal distribution were compared using the $t$ test, and others, using the Mann-Whitney test. The normality of distribution was verified with the Shapiro-Wilk test. Categorical variables were summarized in frequency tables and compared using the Pearson $\mathrm{X}^{2}$ test, also with the Yates correction if the expected number of observations was less than 5. Twelve-month outcomes were expressed using Kaplan-Meyer curves and the log-rank test. The effects of the evaluated parameters on the 12-month incidence of a composite endpoint was assessed using multivariable Cox proportional hazard regression models, with results expressed as hazard ratios and $95 \%$ CIs. Candidate variables were entered into the model, including parameters with a significant influence on univariate analysis: age, atrial fibrillation, body mass index, chronic obstructive pulmonary disease (COPD), current smoking status, diabetes, male sex, glucose levels on admission, hemoglobin levels on admission, heart rate on admission, lack of chest pain on admission, left bundle branch block on admission, left main CAD, left ventricular ejection fraction (LVEF), significant CAD, multivessel CAD, New York Heart Association (NYHA) class III, NYHA class IV, peripheral artery disease, prior myocardial infarction, 
prior revascularization, prior stroke, revascularization during hospitalization, serum creatinine levels on admission, and white blood cell count on admission. Second, after univariate Cox proportional hazard regression, a correlation analysis was performed to eliminate linearly dependent factors (absolute value, $r>0.5$ ). We used the backward stepwise regression method with the significance level set at $P<0.1$ for the variables remaining in the model, provided that the variable "sex" remained in the model regardless of the $P$ value. As sex was the subject of this analysis, we decided that this variable will be most appropriate. For all analyses, a 2-tailed $P$ value less than or equal to 0.05 was considered significant. The Statistica 13 software (StatSoft, Inc., Tulsa, Oklahoma, United States) was used for all calculations.

TABLE 1 Baseline demographic and clinical characteristics of the study patients

\begin{tabular}{|c|c|c|c|c|}
\hline Characteristics & Total population $(n=11021)$ & Women $(n=3858)$ & Men $(n=7163)$ & $P$ value \\
\hline Age, y, mean (SD) & $64.6(9.5)$ & $66.6(9)$ & $63.5(9.6)$ & $<0.001$ \\
\hline Prior MI & $4016(37.3)$ & $1001(26.7)$ & $3015(43.1)$ & $<0.001$ \\
\hline Non-STEMI & $1063(9.9)$ & $311(8.3)$ & $752(10.7)$ & $<0.001$ \\
\hline STEMI & $2678(24.9)$ & $654(17.4)$ & $2024(28.9)$ & $<0.001$ \\
\hline Prior PCI & $3806(35.4)$ & $1043(27.8)$ & $2763(39.5)$ & $<0.001$ \\
\hline Prior CABG & $1284(11.9)$ & $280(7.5)$ & $1004(14.3)$ & $<0.001$ \\
\hline Prior stroke & $614(5.7)$ & $197(5.2)$ & $417(5.9)$ & 0.14 \\
\hline Peripheral artery disease & $1597(14.9)$ & $503(13.5)$ & $1094(15.7)$ & 0.003 \\
\hline Atrial fibrillation & 1905 (17.7) & $642(17.1)$ & $1263(18)$ & 0.26 \\
\hline Arterial hypertension & $8888(81.3)$ & $3282(85.8)$ & $5606(79)$ & $<0.001$ \\
\hline Family history of premature CAD & $2137(20.2)$ & $883(23.9)$ & $1254(18.3)$ & $<0.001$ \\
\hline Diabetes & $3800(35.3)$ & $1434(38.2)$ & $2366(33.7)$ & $<0.001$ \\
\hline Hypercholesterolemia & $8177(75.6)$ & $2877(76)$ & $5300(75.4)$ & 0.49 \\
\hline History of smoking & $5048(46.9)$ & $1246(33.2)$ & $3802(54.2)$ & $<0.001$ \\
\hline Current smoking status & $2447(22.7)$ & $626(16.7)$ & $1821(26)$ & $<0.001$ \\
\hline COPD & $665(6.2)$ & 169 (4.5) & $496(7.1)$ & $<0.001$ \\
\hline CCS class I & $4358(41.7)$ & $1621(44.3)$ & $2737(40.3)$ & $<0.001$ \\
\hline CCS class II & $3679(35.2)$ & $1211(33.1)$ & $2468(36.3)$ & $<0.001$ \\
\hline CCS class III & $2456(23.5)$ & $827(22.6)$ & $1629(24)$ & 0.12 \\
\hline NYHA class I & $6156(57.6)$ & $1998(53.5)$ & $4158(59.8)$ & $<0.001$ \\
\hline NYHA class II & $3117(29.1)$ & $1197(32)$ & $1920(27.6)$ & $<0.001$ \\
\hline NYHA class III & $1302(12.2)$ & $506(13.6)$ & $796(11.4)$ & 0.002 \\
\hline NYHA class IV & $111(1)$ & $34(0.9)$ & $77(1.1)$ & 0.34 \\
\hline LVEF, \%, mean (SD) & $47.1(11)$ & $50(8.8)$ & $45.3(11.6)$ & $<0.001$ \\
\hline LVEF $<35 \%$ & $1159(12.5)$ & $177(5.6)$ & $982(16)$ & $<0.001$ \\
\hline BMI, $\mathrm{kg} / \mathrm{m}^{2}$, median (IQR) & $28(26-31)$ & $29(25-32)$ & $28(26-31)$ & $<0.001$ \\
\hline Serum creatinine, $\mu \mathrm{mol} / \mathrm{l}$, median (IQR) & $80(68-95)$ & $70(60-83)$ & $84(73-99)$ & $<0.001$ \\
\hline GFR, $\mathrm{ml} / \mathrm{min} / 1.73 \mathrm{~m}^{2}$, median (IQR) & $82(67-97)$ & $78(63-93)$ & $84(69-99)$ & $<0.001$ \\
\hline $\mathrm{GFR}<60 \mathrm{ml} / \mathrm{min} / 1.73 \mathrm{~m}^{2}$ & $1768(16.1)$ & $781(20.3)$ & $987(13.8)$ & $<0.001$ \\
\hline Hemoglobin, g/l, median (IQR) & $8.8(8.2-9.3)$ & $8.4(7.9-8.8)$ & $9(8.4-9.5)$ & $<0.001$ \\
\hline White blood cells, $\times 10^{3} / \mu$ l, median (IQR) & $7(5.9-8.4)$ & $6.8(5.7-8.4)$ & $7.1(6-8.4)$ & $<0.001$ \\
\hline
\end{tabular}

Data are presented as number (percentage) of patients unless otherwise indicated.

Abbreviations: BMI, body mass index; CABG, coronary artery bypass grafting; CAD, coronary artery disease; CCS, Canadian Cardiovascular Society; COPD, chronic obstructive pulmonary disease; GFR, glomerular filtration rate; IQR, interquartile range; LVEF, left ventricular ejection fraction; MI, myocardial infarction; NYHA, New York Heart Association; PCI, percutaneous coronary intervention; STEMI, ST-segment elevation myocardial infarction 
TABLE 2 Angiographic characteristics of the study population

\begin{tabular}{|c|c|c|c|c|}
\hline Characteristics & Total population $(n=11021)$ & Women $(n=3858)$ & Men $(n=7163)$ & $P$ value \\
\hline \multicolumn{5}{|l|}{$C A D$} \\
\hline Nonobstructive CAD & $33(3.6)$ & $47(1.8)$ & $25(1.8)$ & $<0.001$ \\
\hline Single-vessel CAD & $3314(30.1)$ & $1014(26.3)$ & $2300(32.1)$ & $<0.001$ \\
\hline Multivessel CAD & $4071(36.9)$ & $1031(26.7)$ & $3040(42.4)$ & $<0.001$ \\
\hline Left main CAD & $668(6.1)$ & $141(3.7)$ & $527(7.4)$ & $<0.001$ \\
\hline Chronic total occlusion & $3077(27.9)$ & $683(17.7)$ & $2394(33.4)$ & $<0.001$ \\
\hline \multicolumn{5}{|l|}{ Diagnostic workup } \\
\hline Bypass angioography & $1284(11.6)$ & $280(7.3)$ & $1004(14)$ & $<0.001$ \\
\hline Fractional flow reserve assessment & $401(3.6)$ & $133(3.5)$ & $268(3.7)$ & 0.43 \\
\hline Intravascular ultrasound & $107(1)$ & $36(0.9)$ & $71(1)$ & 0.77 \\
\hline \multicolumn{5}{|l|}{ Interventional treatment } \\
\hline PCI & 4765 (43.2) & $1388(36)$ & $3377(47.1)$ & $<0.001$ \\
\hline PCI during index hospitalization & $4743(43)$ & $1381(35.8)$ & $3362(46.9)$ & $<0.001$ \\
\hline PCI during next hospitalizations & $709(6.4)$ & $205(5.3)$ & $504(7)$ & $<0.001$ \\
\hline Stent implantation & $4227(38.4)$ & $1246(32.3)$ & $2981(41.6)$ & $<0.001$ \\
\hline Bare-metal stent implantation & $1210(11)$ & $354(9.2)$ & $856(12)$ & $<0.001$ \\
\hline Drug-eluting stent implantation & $3078(27.9)$ & $913(23.7)$ & $2165(30.2)$ & $<0.001$ \\
\hline Drug-eluting balloon & $86(0.8)$ & $17(0.4)$ & $69(1)$ & 0.003 \\
\hline CABG & $997(9)$ & $236(6.1)$ & $761(10.6)$ & $<0.001$ \\
\hline
\end{tabular}

Data are presented as number (percentage) of patients.

Abbreviations: see TABLE 1

TABLE 3 Pharmacotherapy of the study population

\begin{tabular}{|c|c|c|c|c|}
\hline Drug & Total population $(n=11021)$ & Women $(n=3858)$ & Men $(n=7163)$ & $P$ value \\
\hline Acetylsalicylic acid & $8767(90)$ & $2923(88.3)$ & $5844(90.7)$ & $<0.001$ \\
\hline $\mathrm{P} 2 \mathrm{Y} 12$ receptor inhibitor & 4847 (49.7) & $1394(42.1)$ & $3453(53.6)$ & $<0.001$ \\
\hline Oral anticoagulant & $1621(16.6)$ & $495(15)$ & $1126(17.5)$ & 0.002 \\
\hline Nitrate & $39954(40.5)$ & $1384(41.8)$ & 2570 (39.9) & 0.07 \\
\hline$\beta$-Blocker & $9103(93.3)$ & $3092(93.4)$ & $6011(93.3)$ & 0.8 \\
\hline ACEI/ARB & $8528(87.4)$ & $2848(86)$ & $5680(88.1)$ & 0.003 \\
\hline Calcium antagonist & $2377(24.9)$ & $997(30.7)$ & $1380(21.9)$ & $<0.001$ \\
\hline Aldosterone antagonist & $3234(33.8)$ & $979(30.2)$ & $2255(35.7)$ & $<0.001$ \\
\hline Statin & $8598(89.2)$ & $2879(87.9)$ & $5719(89.9)$ & 0.003 \\
\hline Fibrate & $392(4.1)$ & $93(2.8)$ & $299(4.7)$ & $<0.001$ \\
\hline Ezetimibe & $44(0.5)$ & $17(0.5)$ & $27(0.4)$ & 0.51 \\
\hline Diuretic & $4734(48.5)$ & $1586(47.9)$ & $3148(48.9)$ & 0.38 \\
\hline Proton pump inhibitors & $4490(46)$ & $1476(44.6)$ & $3014(46.8)$ & 0.04 \\
\hline Digoxin & $388(4.1)$ & $99(3.1)$ & $289(4.6)$ & $<0.001$ \\
\hline Trimetazidine & $697(7.3)$ & $356(11)$ & $341(5.4)$ & $<0.001$ \\
\hline Ivabradine & $58(0.6)$ & $14(0.4)$ & $44(0.7)$ & 0.11 \\
\hline Oral antidiabetic & 1791 (18.7) & $682(21)$ & 1109 (17.6) & $<0.001$ \\
\hline Insulin & $1182(12.4)$ & $469(14.5)$ & $713(11.3)$ & $<0.001$ \\
\hline
\end{tabular}

Data are presented as number (percentage) of patients.

Abbreviations: ACEI, angiotensin-converting enzyme inhibitor; ARB, angiotensin receptor blocker 
TABLE 4 In-hospital as well as mid- and long-term outcomes of the study population

Outcome

Total population $(n=11021)$

Women $(n=3858)$

Men $(n=7163)$

$P$ value

In-hospital complications

\begin{tabular}{|c|c|c|c|c|}
\hline Any & $164(1.5)$ & $70(1.8)$ & $94(1.3)$ & 0.04 \\
\hline Death & $47(0.4)$ & $17(0.4)$ & $30(0.4)$ & 0.87 \\
\hline MI & $28(0.3)$ & $10(0.3)$ & $18(0.3)$ & 0.94 \\
\hline Target vessel revascularization & $14(0.1)$ & $6(0.2)$ & $8(0.1)$ & 0.54 \\
\hline Stroke & $6(0.1)$ & $2(0.1)$ & $4(0.1)$ & 0.93 \\
\hline Major bleeding & $63(0.6)$ & $33(0.9)$ & $30(0.4)$ & 0.004 \\
\hline Cardiac arrest & $74(0.7)$ & $27(0.7)$ & $47(0.7)$ & 0.86 \\
\hline \multicolumn{5}{|c|}{ 6-month major adverse cardiovascular events } \\
\hline Any & $535(4.9)$ & $151(3.9)$ & $384(5.4)$ & $<0.001$ \\
\hline Death & $285(2.6)$ & $83(2.2)$ & $202(2.8)$ & 0.04 \\
\hline MI & $167(1.5)$ & $47(1.2)$ & $120(1.7)$ & 0.06 \\
\hline Unstable angina & $219(2)$ & $71(1.8)$ & $148(2.1)$ & 0.41 \\
\hline ACS-driven revascularization & $161(1.5)$ & $44(1.1)$ & $117(1.6)$ & 0.04 \\
\hline Stroke & $46(0.4)$ & $10(0.3)$ & $36(0.5)$ & 0.06 \\
\hline \multicolumn{5}{|l|}{ 1-year composite endpoint } \\
\hline Any & $1018(9.2)$ & $287(7.4)$ & $731(10.2)$ & $<0.001$ \\
\hline Death & $449(4.1)$ & $126(3.3)$ & $323(4.5)$ & 0.002 \\
\hline MI & $245(2.2)$ & $67(1.7)$ & $178(2.5)$ & 0.011 \\
\hline Unstable angina & $342(3.1)$ & $101(2.6)$ & $241(3.4)$ & 0.031 \\
\hline ACS-driven revascularization & $270(2.4)$ & $68(1.8)$ & $202(2.8)$ & $<0.001$ \\
\hline Stroke & $97(0.9)$ & $25(0.6)$ & $72(1)$ & 0.06 \\
\hline
\end{tabular}

Data are presented as number (percentage) of patients.

Abbreviations: ACS, acute coronary syndrome; others, see TABLE 1

RESULTS Between January 1, 2006 and December 31, 2016, a total of 13052 patients with confirmed CAD were entered into the PRESAGE. After the exclusion of patients with a significant valvular defect and active malignancy, 11021 patients were included for further analysis. $\mathrm{Pa}$ tients were divided by sex into 2 groups: women (3858 [35\%]) and men (7163 [65\%]). The comparative analysis of clinical and angiographic characteristics of both groups is shown in TABLE 1 . Data on the used pharmacotherapy are presented in TABLE2, and in-hospital and long-term treatment results of both study groups, in TABLE3. Except the higher frequency of significant bleeding in women, no differences in the frequency of deaths and complications were observed between the 2 groups during hospitalization (TABLE4).

Independent risk factors, identified in multivariable analysis and affecting the occurrence of the composite endpoint within 12 months, included: serum creatinine levels, age, white blood cell count, LVEF, prior myocardial infarction, hemoglobin levels on admission, NYHA class III, left main $C A D$, peripheral artery disease, COPD, significant CAD, and NYHA class IV. Sex was not an independent predictor of 12-month outcomes (FIGURES1 and 2) (hazard ratio, 1.08; 95\% CI, $0.89-1.131 ; P=0.45)$. The Kaplan-Meier curves for 12-month outcomes are presented in FIGURE 3 .

DISCUSSION Few studies have compared CCS and previously stable CAD in women and men. ${ }^{7-9}$ The available reports based on registries of treatment records of patients with stable CAD show that women constitute a minority: (CLARIFY [The Prospective Observational Longitudinal Registry of Patients with Stable Coronary Artery Disease], 22.6\%; PCI registry of the German Cardiac Society, 34.6\%; and PRESAGE, 35\%). 2,10 Women included in CAD registries were older than men. However, the mean (SD) age of women compared with that of men was relatively young in both CLARIFY and PRESAGE registries (66.6 [10] vs 63.4 [10.5] years and 66.6 [9] vs 63.5 [9.6] years, respectively). According to some studies, the risk of CAD in women seems to be underestimated, ${ }^{11}$ probably also owing to additional premenopausal risk factors such as pregnancy-related hypertension or polycystic 
Creatinine level (per $10 \mu \mathrm{mol} / \mathrm{l}$ more)

Age (per 5 y more)

White blood cell count (per 1000/ $\mu$ l more)

LVEF (per 5\% less)

Prior MI

Hemoglobin (per $1 \mathrm{mmol} / \mathrm{l}$ less)

NYHA class III

Left main CAD

Peripheral artery disease

COPD

Significant CAD

NYHA class IV

Male sex
HR (95\% CI)

$1.02(1.01-1.03)$

$1.07(1.03-1.12)$

$1.07(1.05-1.1)$

$1.18(1.14-1.22)$

$1.22(1.03-1.45)$

$1.25(1.15-1.36)$

$1.33(1.09-1.62)$

$1.39(1.08-1.79)$

$1.48(1.23-1.77)$

$1.52(1.19-1.95)$

$1.88(1.52-2.33)$

$2.41(1.69-3.44)$

$1.08(0.89-1.31)$

0.45

FIGURE 1 Multivariable analysis of independent risk factors for the composite endpoint at 12 months

Abbreviations: HR, hazard ratio; others, see TABLE 1

Creatinine level (per $10 \mu \mathrm{mol} / / \mathrm{lmore})$

White blood cell count (per 1000/ $\mu$ l more)

Age (per 5 y more)

Hemoglobin (per $1 \mathrm{mmol} / \mathrm{l}$ less)

Significant CAD

LVEF (per 5\% less)

Atrial fibrillation

NYHA class III

COPD

Peripheral artery disease

NYHA class IV

Male sex

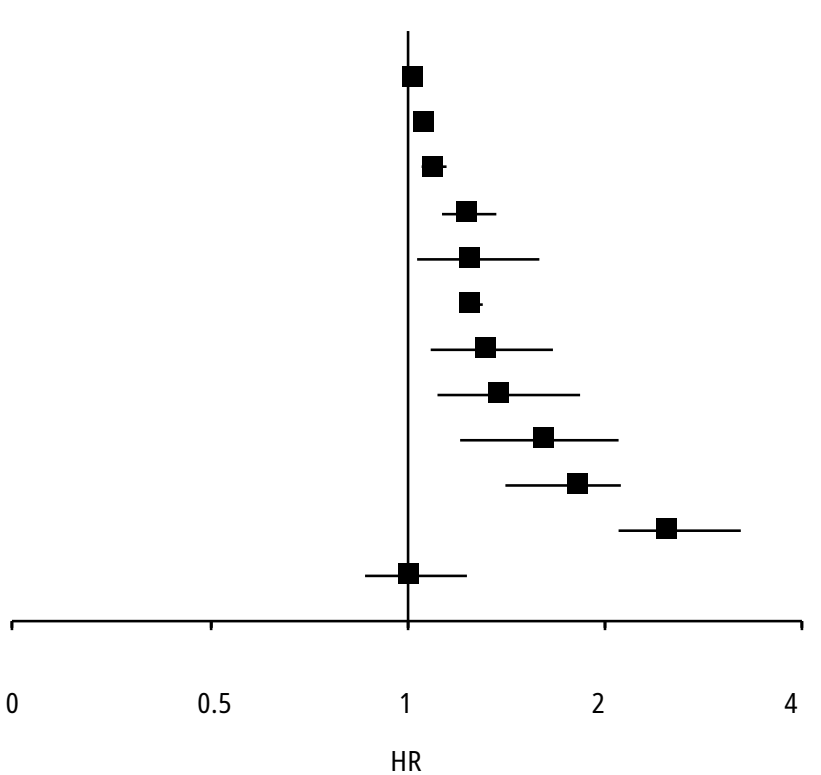

$\begin{array}{ll}\text { HR }(95 \% \text { CI }) & P \text { value } \\ 1.03(1.02-1.04) & <0.001 \\ 1.09(1.07-1.12) & <0.001 \\ 1.13(1.07-1.2) & <0.001 \\ 1.3(1.17-1.45) & <0.001 \\ 1.32(1.04-1.67) & 0.02 \\ 1.32(1.27-1.38) & <0.001 \\ 1.39(1.11-1.74) & 0.004 \\ 1.47(1.16-1.87) & 0.002 \\ 1.69(1.27-2.26) & <0.001 \\ 1.87(1.5-2.34) & <0.001 \\ 3.28(2.25-4.77) & <0.001 \\ 1.01(0.79-1.3) & 0.92\end{array}$

FIGURE 2 Multivariable analysis of independent risk factors for mortality at 12 months Abbreviations: see TABLE 1 and FIGURE 1

ovary syndrome. ${ }^{12-14}$ The results of a comparative analysis of clinical characteristics included in the CLARIFY and PRESAGE registry are consistent. Men more often than women had MI and underwent coronary artery interventions (PCI or $(A B G)$. As a result, men were more frequently diagnosed with heart failure with reduced ejection fraction (LVEF <35\%) than women. In our registry, $12.5 \%$ of patients presented with $\mathrm{LVEF}$ below $35 \%$, which means that one-eighth of patients suffered from heart failure. Moreover, COPD, current smoking status, and peripheral artery disease were also more frequently noted in men. As opposed to men, the main risk factors and comorbidities in women included type 2 diabetes, hypertension, and chronic kidney disease. Considering the results of coronary angiography from our registry, nonsignificant lesions in coronary arteries were more frequently observed in women. Merz et $\mathrm{al}^{12}$ showed that women are more likely to suffer from microcirculatory and endothelial dysfunction, vasospasms, or spontaneous dissections within the coronary arteries. The men included in the PRESAGE, similar to those in the Euro Heart Survey, were characterized by more advanced coronary artery disease than women. ${ }^{8-10}$ The men included in the PRESAGE, similar to other studies, were more often 


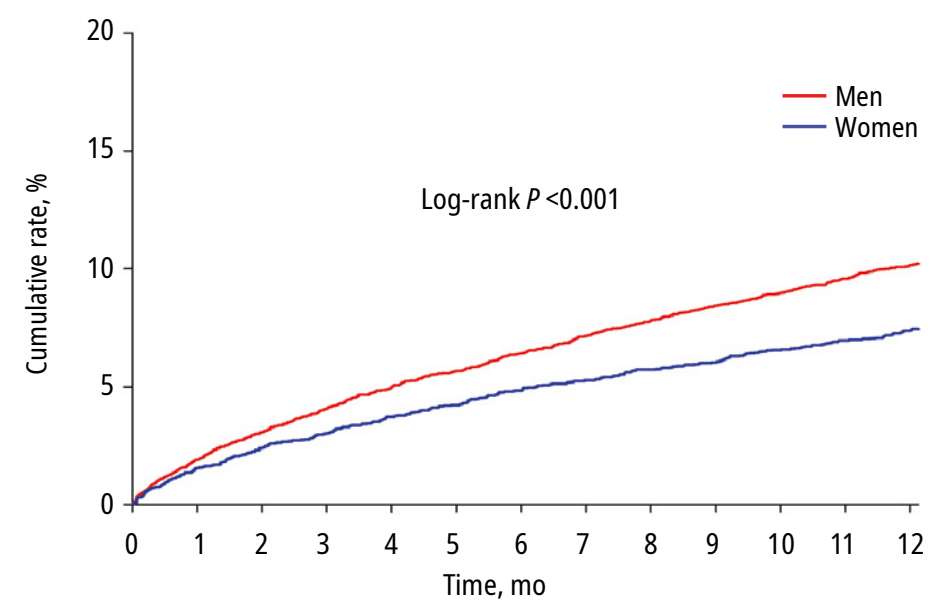

Study groups Number at risk

$\begin{array}{llllll}\text { Men } & 7163 & 6869 & 6703 & 6556 & 6432\end{array}$

$\begin{array}{llllll}\text { Women } & 3858 & 3741 & 3667 & 3624 & 3571\end{array}$

B

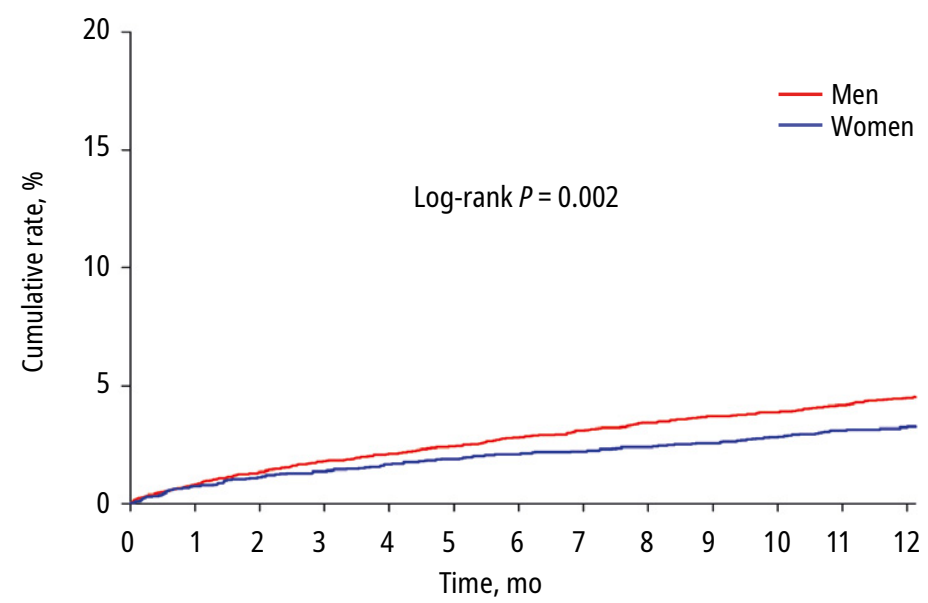

Study groups Number at risk

$\begin{array}{llllll}\text { Men } & 7163 & 7034 & 6961 & 6898 & 6840\end{array}$

$\begin{array}{llllll}\text { Women } & 3858 & 3805 & 3775 & 3759 & 3732\end{array}$

FIGURE 3 Kaplan-Meyer curves for the composite endpoint (A) and mortality (B) in women and men with chronic coronary syndromes at 12 months

deemed eligible for revascularization procedures than women. $.15,16$

There are few studies analyzing in-hospital complications in CCS. ${ }^{15}$ Similar to our analysis, the SAFE-PCI (Study of Access Site for Enhacement of PCI for Women) study showed that women more often required blood transfusions because of perioperative bleeding. ${ }^{15}$

Our study showed no differences in the frequency of use of $\beta$-blockers, aspirin, and P2Y12 receptor inhibitors in the study groups. The analysis of pharmacotherapy demonstrated that almost $50 \%$ of patients received diuretics and almost $30 \%$, aldosterone antagonists. Men more often received angiotensin-converting enzyme inhibitors and statins. Also, the pharmacotherapy analysis in the CLARIFY study showed that women with CCS received less optimal treatment than men.
Long-term prognosis of men and women with CCS remains unclear. In the CLARIFY registry, despite significant differences in clinical characteristics, results of coronary angiography, and revascularization treatment (PCI or CABG), the 12-month prognosis did not differ between particular groups. ${ }^{2}$ There were no differences in the frequency of deaths, MI, unstable angina, or composite endpoints in women and men. ${ }^{2}$ The authors emphasized that only a small percentage of women in their study were deemed eligible for and subjected to coronary angiography and PCI, despite a higher number of risk factors and comorbidities. ${ }^{8}$ Some studies suggested worse prognosis in women undergoing PCI, as the risk of restenosis in the implanted stent is higher in vessels of a smaller diameter, which are actually more common in women. ${ }^{8}$ In the Euro Heart Survey of women with angiographically confirmed CAD, death, MI, or sudden cardiac death were twice as frequent as in men during the 12-month follow-up. In that study, the female sex proved to be an independent risk factor for cardiovascular events only in patients with angiographically confirmed CAD. ${ }^{8}$ In our study, the prognosis for men differed from that for women. Apart from being younger, men presented significant risk factors that worsen long-term prognosis. We observed that the percentage of composite endpoints, including all-cause deaths, was higher in men at 12 months. Significant lesions in coronary arteries, left main CAD, COPD, prior MI, and NYHA class III and IV were identified as independent risk factors in multivariable analysis.

Limitations Our analysis was based on the data of patients treated in a single, high-volume reference center, which, however, has advanced diagnostic and treatment facilities.

Conclusions Women and men with CCS differ in terms of the incidence of risk factors, history of MI, and revascularization treatments. Men were found to have a higher frequency of deaths and composite endpoints during the 12-month follow-up. However, in multivariable analysis, sex was not identified as an independent factor regarding the occurrence of the composite endpoint and death during long-term follow-up.

\section{ARTICLE INFORMATION}

\section{CONFLICT OF INTEREST None declared.}

OPEN ACCESS This is an Open Access article distributed under the terms of the Creative Commons Attribution-NonCommercial-NoDerivatives $4.0 \mathrm{In}$ ternational License (CC BY-NC-ND 4.0), allowing third parties to download articles and share them with others, provided the original work is properly cited, not changed in any way, distributed under the same license, and used for noncommercial purposes only. For commercial use, please contact the journal office at kardiologiapolska@ptkardio.pl.

HOW TO CITE Duda-Pyszny D, Trzeciak P, Desperak P, et al. Comparison of clinical characteristics, in-hospital course, and 12-month prognosis in women and men with chronic coronary syndromes. Kardiol Pol. 2021; 79: 393-400. doi:10.33963/KP.15749 


\section{REFERENCES}

1 Tendera M. Clinical profile of contemporary patients with stable coronary artery disease. Medicographia. 2017; 39: 5-10.

2 Steg PG, Greenlaw N, Tardiff J, Tendera M, et al. Women and men with stable coronary artery disease have similar outcomes: insights from the international prospective CLARIFY registry. Eur Heart J. 2012; 33: 2831-2840.

3 Sedlak T, Lee M, Izadnegahar M, et al. Sex differences in clinical outcomes in patients with stable angina and no obstructive coronary artery disease. Am Heart]. 2013; 166: 38-44.

4 Montalescot G, Sechtem U, Achenbach S, et al. ESC Guidelines on the management of stable coronary artery disease. Eur Heart J. 2013; 34: 2949-3003.

5 Roffi M, Patrono C, Collet JP, et al. ESC Guidelines for the management of acute coronary syndromes in patients presenting without persistent ST-segment elevation: the Task Force for the Management of Acute Coronary Syndromes of the European Society of Cardiology. Eur Heart J. 2016; 37: 267-315.

6 Thygesen $\mathrm{K}$, Alpert JS, Jaffe AS, et al. Third universal definition of myocardial infarction. Eur Heart J. 2012; 33: 2551-2567.

7 Ferrari R, Abergel H, Ford I, et al. Gender- and age-related differences in clinical presentation and management of outpatients with stable coronary artery disease. Int J Cardiol. 2013; 167: 2938-2943.

8 Crea F, Battipaglia I, Andreotti F, et al. Sex differences, presentations and management of ischemic heart disease. Atherosclerosis. 2015; 241: 157-168.

9 Heer T, Hochadel M, Schmidt K, et al. Gender differences in therapeutic recommendation after diagnostic coronary angiography: insights from Coronary Angiography and PCI Registry of German Society of Cardiology. Clin Res Cardiol. 2015; 104: 507-517.

10 Daly C, Clemens F, Sendon L, et al. Gender differences in the management and clinical outcome of stable angina. Circulation. 2006; 113: 490-498.

11 Wojtyniak B, Gierlotka M, Opolski G, et al. Observed and relative survival and 5-years outcomes of patients discharged after acute myocardial infarction: the nationwide AMI-PL database. Kardiol Pol. 2020; 78: 990-998.

12 Merz NB, Shaw LJ, Reis S, et al. Insights from NHLBI-Sponsored Women's Ischemia Syndrome Evaluation (WISE) Study: part II: gender differences in presentation, diagnosis, and outcome with regard to gender-based pathophysiology of atherosclerosis and macrovascular and microvascular coronary disease. J Am Coll Cardiol. 2006; 47: S21-S29.

13 Leuzzi C, Modena G. Coronary artery disease: clinical presentation, diagnosis and prognosis in women. Nutr Metab Cardiovasc Dis. 2010; 20: 426-435.

14 Wada H, Miyauchi K, Daida H. Gender differences in the clinical features and outcomes of patients with coronary artery disease. Expert Rev Cardiovasc Ther. 2019; 17: 127-133.

15 Rao U, Buchanan G, Hoye A, et al. Outcomes after percutaneous coronary intervention in women: are there differences when compared with men? Interv Cardiol. 2019; 14: 70-75.

16 Kunadian V, Qiu W, Lagerqvist Bo, et al. Gender differences and predictors of all-cause mortality after percutaneous coronary intervention (data from United Kingdom and Sweden). Am J Cardiol. 2017; 119: 210-216. 